\title{
Immunocytochemical localization of protamine in the boar testis
}

\author{
J. L. Courtens, L. Plöen* and M. Loir $\dagger$ \\ I.N.R.A. Physiologie de la Reproduction, Nouzilly, 37380 Monnaie, France; *Department of \\ Anatomy and Histology, Swedish University of Agricultural Sciences, S-750 07 Uppsala, Sweden; \\ and $\dagger$ I.N.R.A. Physiologie des poissons, Campus de Beaulieu, 35042 Rennes Cedex, France
}

\begin{abstract}
Summary. Protamine was specifically demonstrated in spermatids and spermatozoa of the boar by immunoelectron microscopy, using anti-boar or anti-ram protamine antisera, and three different direct or indirect labelling techniques. The two isomers of the protamine could not be labelled separately. The protamine is present in the cytoplasm of elongating spermatids and it enters the nuclei throughout the elongation process after possible storage in the cytoplasm or in the nuclear envelope of spermatids, or both. These findings differ from previous observations in other species.
\end{abstract}

Keywords: spermiogenesis; spermatozoa; protamine; immunocytochemistry; electron microscopy; boar

\section{Introduction}

In non-human mammalian species studied so far, protamines are the main basic low molecular weight nucleoproteins of the spermatozoa (Bellvé, 1979). In haploid cells, histones are only present in young spermatids. They are replaced, in elongating spermatids, by intermediate nucleoproteins, also called spermatidal proteins (Meistrich et al., 1981; Loir \& Lanneau, 1984), which in turn are lost and are replaced, in old spermatids, by one or several protamines (Coeling et al., 1972; Monfoort et al., 1973; Kistler et al., 1976; Bellvé \& Carraway, 1978; Sautiere et al., 1984).

These protamines might play a role in the morphogenesis of the sperm head (Fawcett et al., 1971) or in the stabilization of its shape (Loir \& Lanneau, 1978, 1984). They are closely associated with the DNA, thus forming the highly condensed chromatin of the sperm cell (Balhorn et al., 1984). The degree of condensation and the protein composition of the chromatin have been shown to play major roles in fertility (Kettaneh \& Hartl, 1976; Baccetti et al., 1977; Dadoune et al., 1982; Rodriguez et al., 1985). In the bull, ethylene dibromide, a drug which induces modifications of the protamine molecule, or of its synthesis, or of its association with the genome, is a powerful inhibitor of fertility, acting only during limited steps of spermiogenesis (Courtens et al., 1980). In man, in whom the spermatozoa contain several nucleoproteins, and in species possessing several protamines, the situation is probably more complex in regard to the protein-DNA associations and to the temporal synthesis of the several different nucleoproteins (Balhorn et al., 1984). Boar spermatozoa contain two isomers of protamine which differ in composition by only one amino acid residue (Tobita et al., 1982, 1983).

In the present study we attempted to localize these two closely similar molecules in the boar testis, and to define their time-related deposition in the nuclei and the way they enter it. The findings in these respects are compared to those previously reported for the ram (Courtens et al., 1983). 


\section{Materials and Methods}

\section{Isolation of boar protamine}

Spermatozoa $\left(4 \times 10^{10}\right)$ obtained from the cauda epididymidis immediately after castration of boars were sonicated in $300 \mathrm{ml}$ Tris/ $\mathrm{HCl}$ buffer, $\mathrm{pH} 8.0$, containing $3 \mathrm{mM}$-phenylmethylsulphonyl fluoride (Buffer A) for 1 min at maximum power $(150 \mathrm{~W})$. The homogenate was centrifuged $(1500 \mathrm{~g}, 5 \mathrm{~min})$ and resuspended in $25 \mathrm{ml}$ Buffer $\mathrm{A}$, before being resonicated for 9 bursts of $20 \mathrm{sec}$ every $30 \mathrm{sec}$ at $0^{\circ} \mathrm{C}$. After dilution to $150 \mathrm{ml}$ and centrifugation, the pellet was sonicated once in $40 \mathrm{ml}$ Buffer A. The sperm nuclei were resuspended by sonication in $50 \mathrm{ml}$ Buffer A containing $1 \%$ Triton X-100 and left overnight. After centrifugation, the nuclei were incubated in $25 \mathrm{ml} 10 \mathrm{~mm}$-sodium deoxycholate in Buffer A at $37^{\circ} \mathrm{C}$ for $1 \mathrm{~h}$ and then washed twice with $100 \mathrm{ml}$ Buffer $\mathrm{A}$. Thereafter the sperm nuclei, resuspended in $80 \mathrm{ml} B$ uffer A, were purified by centrifugation at $1000 \mathrm{~g}$ for $30 \mathrm{~min}$ through $1.5 \mathrm{M}$-sucrose in Buffer $\mathrm{A}$ (20 ml suspension applied onto $15 \mathrm{ml}$ sucrose). The sperm nuclei obtained under these conditions were clean. After being washed with $100 \mathrm{ml}$ Buffer A, they were treated according to the method of Marushige \& Marushige (1974) as modified by Loir \& Lanneau (1978). The sulphydryl groups in $100 \mathrm{mg}$ of nuclei were reduced by $100 \mathrm{ml} 0.28 \mathrm{M}-2$-mercaptoethanol and then alkylated with $0.5 \mathrm{M}$-iodoacetamide. Of the $80 \mathrm{mg}$ protamines obtained, $30 \mathrm{mg}$ were chromatographed on a CM-52 column (Whatman $1.6 \times 25 \mathrm{~cm})$ using a linear gradient of guanidinium chloride $(0.8$ to $1.4 \mathrm{M})$ in $50 \mathrm{~mm}$-lithium acetate, pH 5 (Marushige \& Marushige, 1978). Protamine was eluted as a rather broad peak by $0.97 \mathrm{M}$-guanidinium chloride. Protein samples were analysed by means of polyacrylamide slab gels in $0.9 \mathrm{M}$-acetic acid and $2.5 \mathrm{M}$-urea, as described by Panyim \& Chalkley (1969). When analysed by this procedure, the purified protamine migrated as two peaks (Fig. 1).

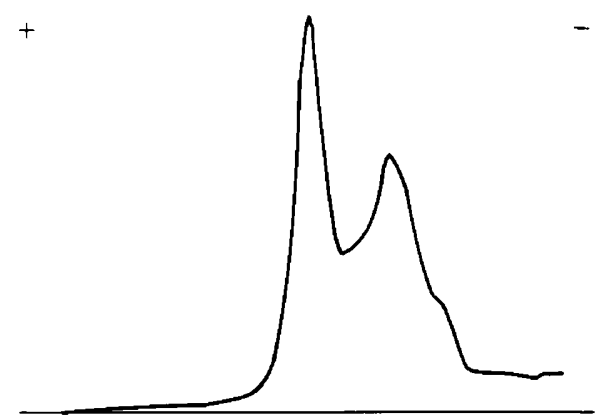

Fig. 1. Electrophoretic pattern of the boar protamines. After chromatography on CM 62, only one symmetrical peak could be observed. It was resolved as two close bands after electrophoresis. The peaks could correspond to the two isomers that differ by only one residue (Tobita et al., 1983).

\section{Immunization procedure}

The boar protamine, dissolved $(1 \mathrm{mg} / \mathrm{ml})$ in $0.25 \mathrm{~N}-\mathrm{HCl}$ containing $0.01 \% \beta$-mercapthoethanol, was dialysed against several changes of $10 \mathrm{~mm}$-Tris $/ \mathrm{HCl}$ buffer, $\mathrm{pH} 7.2$ at $4^{\circ} \mathrm{C}$ for $24 \mathrm{~h}$. To avoid production of autoimmune antibodies directed against the testis (Pelletier et al,, 1981), only castrated male rabbits were used for producing antisera. They were immunized by repeated multiple intradermal injections of the antigen emulsified with enriched ( $5 \mathrm{mg}$ mycobacteria/ml) Freund's complete adjuvant (1 mg protamine/week for 4 weeks). After a 1 month rest period, and 10 days after an intravenous booster injection of an anti-histamine drug (promethazine) $+500 \mu \mathrm{g}$ protamine in PBS, blood samples were taken. The antisera precipitated $0.85-1.20 \mathrm{mg}$ protein $/ \mathrm{ml}$.

Rabbit anti-ram protamine antisera were obtained as previously described (Courtens et al., 1983).

\section{Electron microscopy}

Immediately after castration, boar testes were fixed by immersion in $4 \%$ glutaraldehyde in $0.1 \mathrm{M}$-cacodylate buffer for $30 \mathrm{~min}$ at $20^{\circ} \mathrm{C}$, or in PAF $\left(2.3 \%\right.$ picric acid, $10 \%$ paraformaldehyde, $0.1 \mathrm{M}$-cacodylate buffer) for $4 \mathrm{~h}$ at $4^{\circ} \mathrm{C}$. The pieces were washed overnight in cold cacodylate buffer and then rapidly dehydrated through a series of alcohol and embedded in Epon 812. Some of the ultrathin sections mounted on gold or nickel grids were etched by flotation on 3\% hydrogen peroxide for 5-15 min before the labelling procedure. Various other fixatives which gave better anatomical preservation were used, but they gave no immunostaining. 


\section{Immunocytochemistry}

Direct method. Crude uncomplemented antisera were bound at $\mathrm{pH} 9.2$ to colloidal gold, prepared according to the method of Stathis \& Fabricano (1958) $(0.6 \mu \mathrm{l}$ antiserum $/ \mathrm{ml}$ gold suspension). This concentration was chosen as slightly under optimum, after titration according to the method of Bendayan (1981). After $3 \mathrm{~min}, 5 \%$ purified bovine casein and PBS buffer, concentrated 10 times, were added to the suspension to give respective final concentrations of $1 \%$ casein and once concentrated buffer, $\mathrm{pH} 8 \cdot 3$.

Ultrathin sections, mounted on gold or nickel grids, were sequentially floated on $1 \%$ casein in PBS, pH 8.3, for 15-30 min at room temperature, then on the gold-antiserum suspension for $45 \mathrm{~min}$, then on PBS for $5 \mathrm{~min}$, and finally on distilled water ( 4 changes). They were observed at $40 \mathrm{kV}$ without counterstaining.

Indirect methods. Protein A was coupled to gold particles at $\mathrm{pH} 6 \cdot 0$. The concentration of the protein was chosen to be slightly under binding saturation, and casein and PBS, $\mathrm{pH} 7 \cdot 3$, were added as described above. The sections were floated on $1 \%$ buffered casein for $30 \mathrm{~min}$ and were then incubated for $1-4 \mathrm{~h}$ in antiserum diluted (1/100 to $1 / 2000)$ in PBS, $\mathrm{pH} 8 \cdot 3$, containing $1 \%$ casein. After intensive washing in PBS, they were floated on the gold-protein A suspension for $45 \mathrm{~min}$ to $5 \mathrm{~h}$ at room temperature, or overnight at $5^{\circ} \mathrm{C}$. They were observed after 4 washes with distilled water.

For immunoperoxidase staining, $1 \%$ casein in PBS was adsorbed to the sections which were then incubated with the first antiserum, diluted $1 / 100$, in PBS, $\mathrm{pH} 8 \cdot 3$, containing $1 \%$ casein. Thereafter the grids were intensively washed through PBS and incubated in 1/40 goat antirabbit immunoglobulins coupled to horseradish peroxidase diluted in $1 \%$

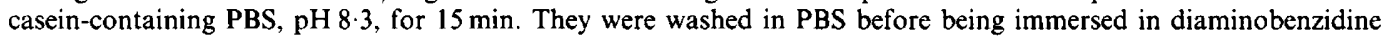
$(0.12 \mathrm{mg} / \mathrm{ml})$ in PBS, $\mathrm{pH} 7.3$, for $5 \mathrm{~min}$. Hydrogen peroxide was then added to a final concentration of $1 \times 10^{-5} \%$ and incubation was continued for $5 \mathrm{~min}$ with gentle agitation. The grids were washed with distilled water, dried, and exposed to osmium tetroxide vapour at $60^{\circ} \mathrm{C}$ for $45 \mathrm{~min}$. They were observed without counterstaining.

Controls. Controls included the use of primary antibody previously coupled to an excess antigen, and the omission of each of the different steps when the indirect techniques were used.

Semi-quantitation of the labelling. The numbers of colloidal grains per nuclear section were counted on sections labelled with the direct technique (antiserum coupled to the gold particles), since this one-step method is more reliable for quantitation than the several-step indirect methods. Care was taken to use the same fixatives, reagents and conditions for comparison of the different steps which never occurred together on the same section. The steps of spermiogenesis are those described by Courtens \& Loir (1981). During elongation of the spermatids, the labelling was not uniform inside the nuclei (see 'Results'). Therefore, the quantitation can only be described as semi-quantitative. This is evident in the results with higher standard deviation values for those particular steps of spermiogenesis. However, this did not interfere with the ratios of grain number per nucleus/grain number per nuclear envelope which correspond to the same sections (Fig. 2).

\section{Results}

With the technical precautions discussed below, the three methods and the two antibodies used in this work gave similar exclusive locations in spermatids and in spermatozoa.

The choice of the competition protein that was used to saturate non-specific sites on sections was of prime interest. In a preliminary set of experiments, lower concentrations $(0 \cdot 01-0 \cdot 1 \%)$ of casein were used and resulted in staining of most of the nuclei, as well as of some inclusions in the lymphocytes. Identical non-specific staining was obtained when bovine serum albumin was used instead of casein, even with a $1 \%$ concentration. The non-specific adsorptions observed could have been due to the presence of very basic proteins in the testis and to the fixation procedure used, which possibly did not completely neutralize the highly positively charged residues. For this reason, the acidic bovine casein was chosen for preadsorption to the sections, and the $\mathrm{pH}$ of the incubation media was maintained close to the $\mathrm{pl}$ of the immunoglobulins. Under these conditions, complete or almost complete abolition of the staining occurred in the inhibition tests (Fig. 6).

No differences in the labelling intensities were observed when the sections were etched with hydrogen peroxide before the labelling procedure, but the anti-ram protamine resulted in stronger labelling than the anti-boar protamine used under the same conditions.

The younger spermatid nuclei in which immuno-labelling occurred with both antibodies were at steps 9-10, i.e. at the time when the manchette was present and elongation of the nucleus had already begun. Very few grains of gold, or osmium deposit, were found spread over the chromatin at those steps.

In step 10 spermatids, aggregates of both central and peripheral chromatin were stained, as well as parts of the nuclear envelope. The labelling of the peripheral anterior parts of the nucleus was 


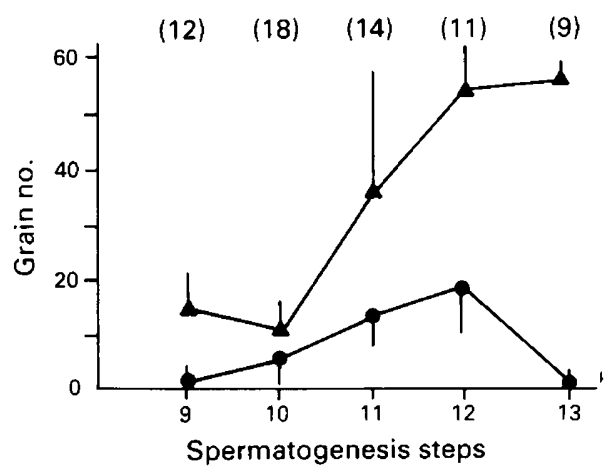

Fig. 2. Grain number/nuclear section related to the steps of spermiogenesis. ( $\Delta$ ) Total number per section of nucleus. (1) Grains bound to or in proximity to the nuclear envelope in the same sections. Values are means \pm s.d. for the no. of sections given in parentheses. In nuclear elongation stages (10-12), about one-third of the labelling is located near the nuclear envelope. In elongated nuclei (13 and after) the labelling is mostly present on the chromatin.

more pronounced than that in the centre (Figs 3 and 7), and about $50 \%$ of the labelling was bound to the nuclear envelope (Fig. 2).

In step 1 1-12 spermatids, the labelling of the anterior-central parts of the nuclei was stronger than in the former steps and this stronger labelling was located more and more distally during the late step 12, i.e. when the manchette was slipping backwards along the nucleus (Fig. 4). The staining of the nuclear envelope was weaker than in the preceding steps, irrespective of the technique used (compare Figs 3 and 7).

The immunolabelling was uniform in the nuclei of the oldest spermatids, after the disappearance of the manchette, at steps 13 (Figs 5 and 9) and older, and also in the nuclei of spermatozoa. The nuclear envelope was only weakly stained or not at all stained in these stages.

Sparse labelling was present in the cytoplasm of the spermatids when anti-boar protamine was used, and this labelling could not be distinguished from the background when inhibition tests were performed (Fig. 6). Anti-ram protamine gave rise to stronger specific staining of the spermatid cytoplasm from steps 10 to 12 of spermiogenesis. The labelling was located mostly close to and posterior to the manchette, but, because of the fixation procedure used, is was impossible to ascertain what cytoplasmic organelles were labelled (Figs 7 and 8). The immuno-stains were absent from the cytoplasm of step 13 (Fig. 9) and older spermatids.

\section{Discussion}

The electrophoretic pattern of the protamine which we have purified is in accordance with the results of Tobita et al. (1983), pointing to the occurrence of two protamine isomers in the boar. These two proteins, which are composed of 50 amino acids, differ in composition only by the absence of the C-terminal half-cysteine in the minor component (Tobita et al., 1982). It therefore appears to be a difficult challenge to raise different antibodies against each of these molecules.

The present immunolocalization of boar protamine by two different antisera, directed against two species-specific protamines, is not surprising, since protamines are highly conservative proteins which are known to cross-react with different antibodies (Rodman et al., 1984). However, the observations that protamine is present in early elongating spermatids of the boar, and the finding of a quite clear-cut double location (first near the nuclear envelope and then in the chromatin) are new. 

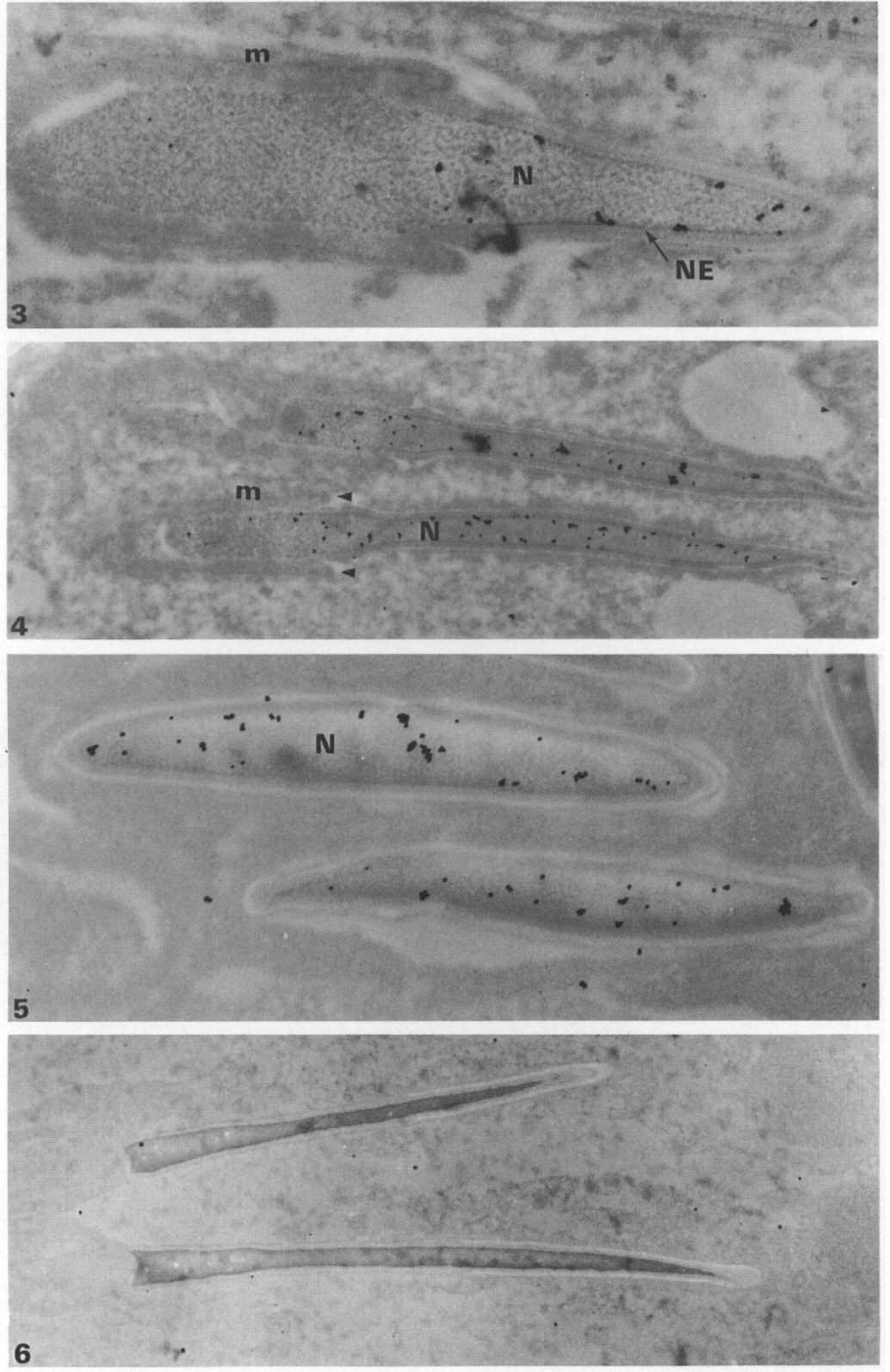

Figs 3-6. Sections were labelled with anti-boar protamine antiserum coupled to colloidal gold (Figs $3,4,5$ ) or with the same antiserum saturated with boar protamine and coupled to colloidal gold (Fig. 6).

Fig. 3. Step 10 spermatid. Most grains are located in the anterior part of the nucleus $(\mathrm{N})$ and along the nuclear envelope $(\mathrm{NE}) . \mathrm{M}=$ manchette. $\times 18000$.

Fig. 4. Early step 12 spermatids. The manchette (arrows) has begun its migration towards the posterior part of the nucleus which is now labelled for protamine. $\times 14000$.

Fig. 5. Step 13 spermatid. Grains are bound to the entire chromatin $(\mathrm{N})$ and few are present on the nuclear envelope. $\times 18000$.

Fig. 6. Control section through step 14 spermatids. $\times 9000$. 

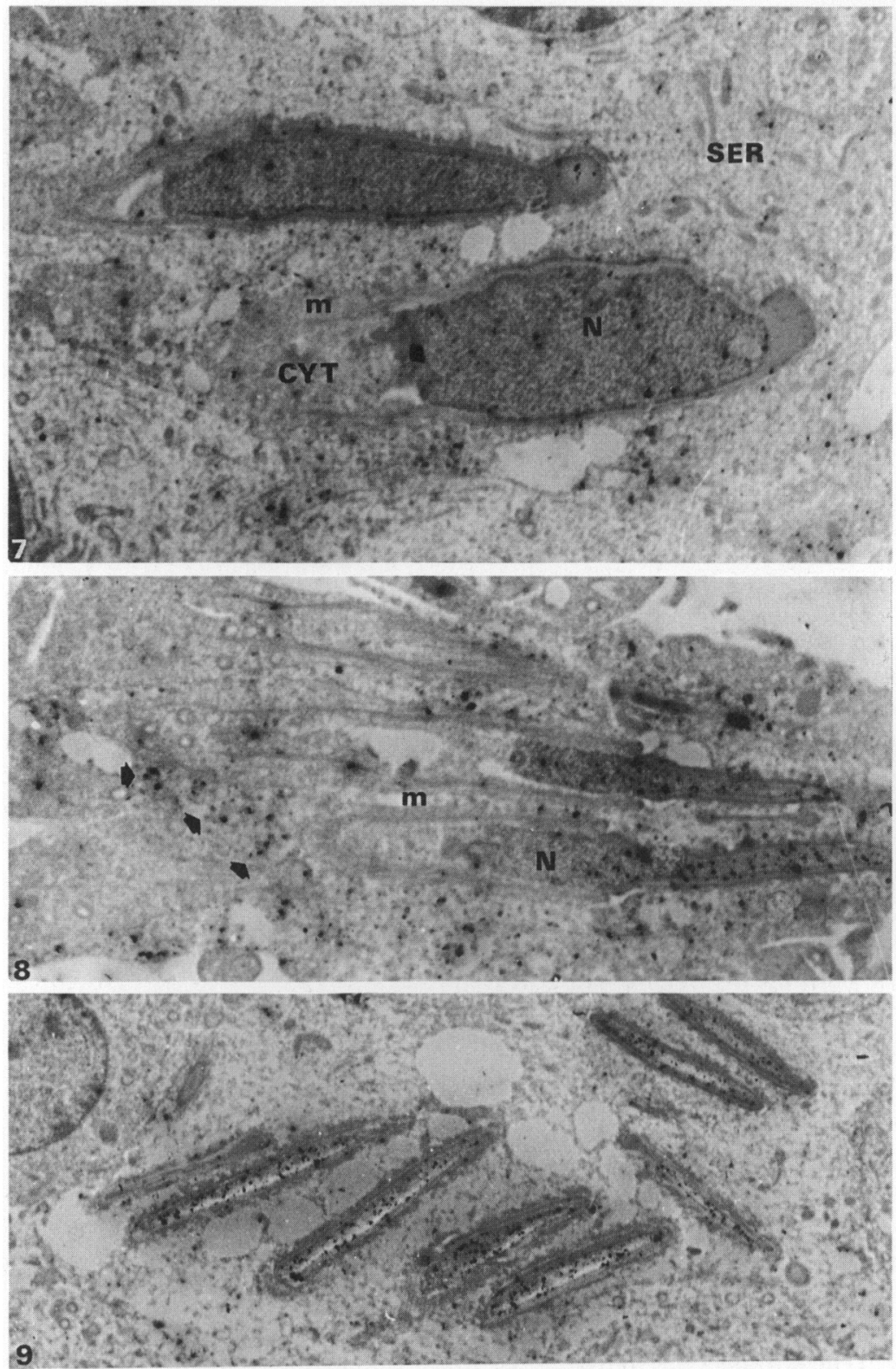

Figs 7-9. The sections were labelled with rabbit anti-ram protamine antiserum, followed by anti-rabbit immunoglobulins coupled to peroxidase.

Fig. 7. Step 10 spermatids. The cytoplasm (CYT) as well as the nuclei $(\mathrm{N})$ are labelled. SER = Sertoli cell. $\mathrm{m}=$ manchette. $\times 7000$.

Fig. 8. Step 11-12 spermatids. Most of the cytoplasmic labelling (arrows) is concentrated posterior to the manchette $(\mathrm{m})$. The nuclear labelling is equivalent to that in Fig. $4 . \times 7500$.

Fig. 9. Step 13 spermatids. The cytoplasmic labelling is very sparse. Nuclei are strongly labelled. $\times 6500$. 
In a previous study the anti-ram protamine used in the present work could only recognize protamine in step 12 and older ram spermatids (Courtens et al., 1983) and, unlike the boar, no specific labelling of the ram spermatid nuclear envelopes was observed. This rules out the possibility that antibodies directed against the nuclear envelope were present in our antisera (the nuclear membranes were removed before protamine extraction with Triton X-100 and sodium desoxycholate). Such antibodies should bind to all the nuclear envelopes present in the testis of both species, or at least they should bind to the nuclear envelope of the spermatids at any stages of spermiogenesis. The only nuclear envelopes stained were those in elongating spermatids and only weak labelling was observed in old spermatids and spermatozoa with antibodies against ram and boar protamine. A possible explanation for the binding to the nuclear envelope could be that the protamine follows or is stored in this particular pathway before it enters the nucleus. This hypothesis is strengthened by the previous cytochemical observations that in several mammalian species the nuclear envelope of spermatids is one of the pathways by which some of the intermediate nucleoproteins flow in and out of the nucleus (Courtens, 1982).

With the technical limitations discussed above, it is not known whether only one or the two isomers of the protamine are present together in early elongating spermatids, and whether they are synthesized at the same time or not, as in the mouse (Balhorn et al., 1984), when no RNA synthesis can be demonstrated in other species (Monesi, 1965; Loir, 1972). The counting of the number of grains per nuclear section, which reveals that the incorporation in the nuclei is almost constant from steps 9-10 to 13 of spermiogenesis, is not helpful in answering this question. In the trout (Iatrou \& Dixon, 1977), and the mouse (Kleene et al., 1984), long-lived protamine mRNAs are activated immediately before the rapid synthesis of the protein. In the boar, the synthesis of the protamine appears to be a long process, which could hardly be regulated the same way. It is possible that the two isomers of the boar are synthesized sequentially, and that these two different syntheses are controlled separately. However, this hypothesis is not unique. In the ram, a cytoplasmic location of the protamine was difficult to establish, possibly because of rapid transfer of newly synthesized proteins to the nuclei, and of a very short period of synthesis (Courtens et al., 1983). In the boar, the strong cytoplasmic labelling obtained with one of the same antisera, at the time when the progressive nuclear incorporation was proceeding, might indicate that one or two of the isomers are stored in the cytoplasm before entering the nuclei. In this respect, the present results are not compatible with our previous hypothesis that boar protamine is stored in cytoplasmic double membrane-limited granules before entering the nucleus (Courtens, 1982). Such granules, which are also present in a lizard (Courtens \& Depeiges, 1985) and in the tapir (Ploen \& Courtens, 1986), were never labelled for protamine.

The considerable attempts to understand how the nucleus of the mammalian spermatid is shaped have led to the conclusion that, even if some cytoplasmic organelles are involved (Courtens, 1984), the final role in nuclear shaping is devoted to the $\mathrm{S}-\mathrm{S}$ cross-linking of spermatidal proteins (Loir \& Lanneau, 1984), while the protamines that generally enter the already shaped nuclei (Courtens $\&$ Loir, 1981) first stabilize the chromatin and then become involved in its final packaging (Subirana, 1982).

Thus the presence of protamine in elongating spermatids of the boar raises the question of its functions at that time of spermiogenesis. In this species, 5 different spermatidal proteins are extractable from sonication-resistant spermatid nuclei (Lanneau \& Loir, 1982), but few data are available concerning the exact timing of their deposition (Courtens, 1982) and no sequence is known. Can one or several spermatidal proteins share common parts of the protamine amino acid sequence, or be equivalent to a preprotamine as proposed by Yelick et al. (1987)?

The boar is not the only species possessing spermatid nuclei containing protamine and intermediate proteins at the same time. In the rat, the spermatidal protein TP3 is also present together with the protamine for several days in old spermatids (Grimes, 1986). No model of interaction of DNA with more than one protein (the protamine) is available for spermatids and spermatozoa. The binding of protamine to mammalian DNA occurs at residues 13 to 36 . This central part of the 
molecule is common to the mammals studied so far (Sautiere et al., 1984), and species differences are mainly located at the C-terminal ends of the protamines (Rodman et al., 1984). These differences are therefore probably of little importance for the binding to the DNA, but they might play some unknown roles.

The possibility that the protamine alone, or co-acting with spermatidal proteins, may be involved in nuclear shaping of boar spermatids remains to be demonstrated. The labelling of the chromatin in the present study was restricted to the most condensed parts of the nuclei in elongating and elongated spermatids and that labelling progressed from the anterior part of the nuclei, backwards. This might indicate separate attachment sites of spermatidal proteins and of protamine to the DNA.

This work was supported by a grant from the Swedish Council for Forestry and Agricultural Research. We thank Dr H. Rodriguez for critical reading of the manuscript and B. Hellmén for aid with the photographic work.

\section{References}

Baccetti, B., Renieri, T.R., Rosati, F., Selmi, M.G. \& Casanova, S. (1977) Further observations on the morphogenesis of the round-headed human spermatozoa. Andrologia 9, 255-264.

Balhorn, R., Weston, S., Thomas, C. \& Wyrobeck, A.J. (1984) DNA packaging in mouse spermatids. Expl Cell Res. 150, 298-308.

Bellvé, A.R. (1979) The molecular biology of spermatogenesis. Oxford Rev. Reprod. Biol. 1, 159-260.

Bellvé, A.R. \& Carraway, R. (1978) Characterization of two basic chromosomal proteins isolated from mouse spermatozoa. J. Cell Biol. 79, 177a, abstr.

Bendayan, M. (1981) Ultrastructural localization of nucleic acids by the use of enzyme-gold complex. $J$. Histochem. Cytochem. 29, 531-541.

Coeling, J.P., Monfoort, C.H., Rozijn, T.H., GeuversLeuven, J.A., Schiphof, R., Steyn-Parvé, E.P., Braunitzer, G., Schrank, P. \& Ruhfus, A. (1972) Isolation and partial characterization of a basic protein from bovine sperm heads. Biochim. Biophys. Acta 285, $1-14$.

Courtens, J.L. (1982) Some nucleocytoplasmic exchanges during spermiogenesis of boar, ram and stallion. Gamete Res. 5, 137-152.

Courtens, J.L. (1984) La différenciation des spermatides. In Developpements recents de l'Endocrinologie du Testicule (Coll. INSERM No. 123), pp. 57-85.

Courtens, J.L. \& Depeiges, A. (1985) Spermiogenesis of the lizard lacerta vivipara. J. Ultrastruct. Res. 90, 203-220.

Courtens, J.L. \& Loir, M. (1981) A cytochemical study of nuclear changes in boar, bull, goat, mouse, rat and stallion spermatids. J. Ultrastruct. Res. 74, 327-340.

Courtens, J.L., Amir, D. \& Durand, J. (1980) Abnormal spermiogenesis in bulls treated with ethylene dibromide: an ultrastructural and cytochemical study. $J$. Ultrastruct. Res. 71, 103-115.

Courtens, J.L., Delaleu, B., Dubois, M.P., Lanneau, M., Loir, M. \& Rozinek, J. (1983) Immunocytochemical localization of protamine in the spermatids of the ram. Gamete Res. 8, 21-28.

Dadoune, J.P., Alfonsi, M.F. \& Terquem, A. (1982) PTA cytochemical characterization of lysine residues in the nucleus of spermatids and ejaculated spermatozoa in man. Biol. Cell. 45, 156a abstr.

Fawcett, D.W., Anderson, W. \& Phillips, D.M. (1971) Morphogenetic factors influencing the shape of the sperm head. Devl Biol. 26, 220-251.

Grimes, S.R. (1986) Nuclear proteins in spermatogenesis. Comp. Biochem. Physiol. 83B, 495-500.

Iatrou, K. \& Dixon, G.H. (1977) Messenger RNA sequences in the developing trout testis. Cell 10, 433441 .

Kettaneh, N.P. \& Hartl, D.L. (1976) Histone transition during spermiogenesis is absent in segregation distorter males of Drosophila melanogaster. Science, N.Y. 193, 1020-1021.

Kistler, W.S., Keim, P.M. \& Heinrikson, R.L. (1976) Partial structural analysis of the basic chromosomal protein of rat spermatozoa. Biochim. Biophys. Acta 427, 752-757.

Kleene, K.C., Distel, R.J. \& Hecht, N.B. (1984) Translational regulation and deanylation of a protamine mRNA during spermiogenesis in the mouse. Devl Biol. 105, 71-79.

Lanneau, M. \& Loir, M. (1982) An electrophoretic investigation of mammalian spermatid-specific nuclear proteins. J. Reprod. Fert. 65, 163-170.

Loir, M. (1972) Métabolisme de l'acide ribonucléique et des proteines dans les spermatocytes et les spermatides du bèlier (Ovis Aries). I. Incorporation et devenir de la 3H-Uridine. Annls Biol. anim. Biochim. Biophys. 12, 203-219.

Loir, M. \& Lanneau, M. (1978) Partial characterization of ram spermatidal basic nuclear proteins. Expl Cell. Res. 115, 231-243.

Loir, M. \& Lanneau, M. (1984) Structural function of the basic nuclear proteins in ram spermatids. $J$. Ultrastruct. Res. 86, 262-276.

Marushige, Y. \& Marushige, K. (1974) Properties of chromatin isolated from bull spermatozoa. Biochim. Biophys. Acta 340, 498-508.

Marushige, Y.\& Marushige, K. (1978) Phosphorylation of sperm histone during spermiogenesis in mammals. Biochim. Biophys. Acta 518, 440-449.

Meistrich, M.L., Trostle, P.K. \& Brock, W.A. (1981) Association of nuclear protein transitions with 
chromatin changes during rat spermatogenesis. In Bioregulators of Reproduction, pp. 151-167. Eds G. Jagiello \& H.J. Vogel. Academic Press, New York.

Monfoort, C.H., Schipkof, R., Roxijn, T.H. \& SteynParvé, E.P. (1973) Amino acid composition and carboxyl-terminal structure of some basic chromosomal proteins of mammalian spermatozoa. Biochim. Biophys. Acta 322, 173-177.

Monesi, V. (1965) Synthetic activities during spermatogenesis in the mouse: RNA and protein. Expl Cell Res. 39, 197-224.

Panyim, S. \& Chalkley, R. (1969) High resolution acrylamide gel electrophoresis of histones. Archs Biochem. Biophys. 130, 337-346.

Pelletier, R.M., Nemirovsky, M.S., Calvert, R. \& Hugon, J.S. (1981) Effects of immunization with Freund's complete adjuvant and isologous spermatozoa on the seminiferous epithelium and blood-testis barrier in guinea pigs. Anat. Rec. 199, 197-211.

Plöen, L. \& Courtens, J.L. (1986) Comparative aspects of mammalian spermiogenesis. Scanning Electron Microscopy 2, 639-652.

Rodman, T.C., Pruslin, F.H. \& Allfrey V.G. (1984) Protamine-DNA association in mammalian spermatozoa. Expl Cell Res. 150, 269-289.

Rodriguez, H., Ohanian, C. \& Bustos-Obregon, E. (1985) Nuclear chromatin decondensation of spermatozoa in vitro: a method for evaluating the fertilizing ability of ovine semen. Int. J. Androl. 8, 147-158.

Sautiere, P., Belaiche, D., Martinage, A. \& Loir, M. (1984) Primary structure of the ram (Ovis aries) protamine. Eur. J. Biochem. 144, 121-125.

Stathis, E.C. \& Fabricano, A. (1958) Preparation of colloidal gold. Chem. Ind. Lond. 27, 860-861.

Subirana, J.A. (1982) Nuclear proteins in spermatozoa and their interaction with DNA. In The Sperm Cell, Fertilizing Power, Surface Properties, Motility, Nucleus and Acrosome, Evolutionary Aspects, pp. 197-213. Ed. J. Andre. Martinus Nijhoff, The Hague.

Tobita, T., Nomoto, M., Nakano, M. \& Ando, T. (1982) Isolation and characterization of nuclear basic protein (protamine) from boar spermatozoa. Biochim. Biophys. Acta 707, 252-258.

Tobita, T., Tsutsumi, H., Kato, A., Suzuki, H., Nomoto, M., Nakano, M. \& Ando, T. (1983) Complete amino acid sequence of boar protamine. Biochim. Biophys. Acta 744, 141-146.

Yelick, P.C., Balhorn, R., Johnson, P.A., Corzett, M., Mazrimas, J.A., Kleene, K.C. \& Hecht, N.B. (1987) Mouse protamine 2 is synthesized as a precursor whereas mouse protamine 1 is not. Molec. cell. Biol. 7, 2173-2179.

Received 22 June 1987 